SEMBLANZAS 



\title{
LA AVENTURA DEL BOLETÍN INFORMATIVO DEL SEMINARIO DE DERECHO POLÍTICO DE LA UNIVERSIDAD DE SALAMANCA (1954/1964)
}

\author{
PABLO LUCAS MURILLO DE LA CUEVA \\ Catedrático de Derecho Constitucional \\ Magistrado del Tribunal Supremo \\ Académico de número de la Real Academia de Ciencias Morales y Políticas
}

TRC, núm. 46, 2020, pp. 587-611

ISSN 1139-5583

\section{SUMARIO}

I. Una explicación necesaria. II. El Boletín en cifras y datos. III. El espíritu del Boletín. IV. El Boletín por dentro. V. La impresión de conjunto. VI. Las razones de su supervivencia. VII. Referencia final.

\section{UNA EXPLICACIÓN NECESARIA}

Hace ya muchos meses, Óscar Alzaga Villaamil me propuso que escribiera un artículo sobre el Boletín Informativo del Seminario de Derecho Político de la Universidad de Salamanca. Sabía que dispongo de la colección que conservaba mi padre, que reunía todos los números que se publicaron salvo un par de ellos y me consideró en condiciones de entregar un texto que, sin ser igual, guardara sintonía con el que escribió Nicolás Pérez-Serrano Jáuregui sobre la Revista de Derecho Público ${ }^{1}$. Aunque tuve dudas de si sería capaz de responder debidamente a la confianza que implica esa iniciativa y el trabajo jurisdiccional no me deja mucho tiempo para actividades como ésta, me decidí de inmediato y acepté el encargo.

Me movió, claro está, el agradecimiento a Óscar Alzaga Villaamil por haber pensado en mí. Pero, además, sucede que en el Boletín trabajó con la intensidad que le caracterizaba mi padre, que fue su subdirector, incluso cuando ya había

1 Pérez-Serrano Jáuregui, N., «La Revista de Derecho Público: un oasis de libre expresión del Derecho Político entre dictaduras (1932/1936)» y se encuentra en el n. ${ }^{\circ}$ 38/2016, pp. 453-469, de esta revista. 
accedido a la cátedra de Derecho Político de la Universidad de Santiago de Compostela que ganó en diciembre de 1957. Él recordaba —y así nos lo contó más de una vez y lo escribió en su Curso de Derecho Político ${ }^{2}$ - con extraordinario cariño el Seminario de Derecho Político de Salamanca: era, decía, un hogar intelectual liberal que atrajo a estudiantes y profesores. Y el mismo sentimiento guardaba respecto del Boletín que surgió en su seno y de lo que representó en la Universidad española de ese tiempo. También me vino a la memoria que, como recuerda Raúl Morodo, secretario de redacción desde $1957^{3}$, mi abuelo Victoriano Lucas de la Cruz, catedrático de Matemáticas en el Instituto Fray Luis de León de Salamanca ${ }^{4}$, se ocupaba de ordenar los textos, de las pruebas y de su corrección y, en general, de la buena marcha de los trabajos de la imprenta que en Salamanca fue la de $E l$ Adelanto, periódico local. En fin, reparé en las veces en que siendo yo muy niño mi padre o mi abuelo Victoriano o los dos juntos me llevaban al Seminario de Derecho Político, en la Facultad de Derecho, entonces en la sede actual de la Facultad de Traducción y Documentación, entre las calles Francisco de Vitoria y Libreros, y mientras ellos se ocupaban de sus quehaceres, seguramente también del Boletín, yo me entretenía revolviendo en la mesa en la que me dejaban, abriendo sus cajones y descubriendo objetos tan interesantes como lápices con una punta azul y otra roja, grapadoras, secantes, tinteros e, incluso, frascos de lo que, según me dijeron al quitármelos de las manos, al mismo tiempo que los tinteros, era goma arábiga.

Debo decir que, antes de que Óscar Alzaga Villaamil me propusiera escribir estas líneas, me dispuse a hacerme con una copia de los $n .{ }^{\circ} 1$ y 27 que faltaban en la biblioteca de mi padre. Para hacerme con ellas, pedí a Ángela Figueruelo Buriezo, catedrática de Derecho Constitucional de la Universidad de Salamanca, pensando que estarían en su Biblioteca, que me las consiguiera y, efectivamente, sus gestiones tuvieron éxito.

Tomé la iniciativa porque en el curso del homenaje que el Centro de Estudios Políticos y Constitucionales dedicó en la primavera de 2018 a Pedro de Vega, tras recordar Raúl Morodo en su intervención el Boletín, el Director del Centro, Benigno Pendás García, manifestó su disposición para publicarlo nuevamente. Dado que el Centro solamente disponía de algunos números acepté facilitar los que faltaran de los que yo tenía. Posteriormente, ya con Yolanda Gómez al frente, el Centro decidió digitalizarlos para ponerlos a disposición de cualquier persona interesada en su consulta y que fueran accesibles de forma gratuita. Y,

2 Lucas Verdú, P., Curso de Derecho Político, vol. I. Tecnos, Madrid, 1972, p. 185.

3 Morodo, R., Atando cabos. Memorias de un conspirador moderado (I). Taurus, Madrid, 2001, p. 149. Enrique Tierno Galván, en la carta que escribió a mi padre, publicada en la Revista de Política Comparada, n. ${ }^{\circ} 10-11 / 1984$, p. 15 , también recuerda la ayuda de mi abuelo en la publicación del Boletín.

4 En abril de 1934 y en enero de 1936, siendo Ministro de Instrucción Pública el salmantino Filiberto Villalobos en los gabinetes Samper y Portela Valladares, fue nombrado Director General de Primera Enseñanza. Dimitió del cargo en diciembre de 1934 y en febrero de 1936, al cesar el ministro. 
efectivamente, el Boletín completo fue digitalizado por el Boletín Oficial del Estado a instancias del Centro de Estudios Políticos y Constitucionales y hoy en día se puede acceder libremente a todos sus números en la Biblioteca Jurídica Digital ${ }^{5}$.

No cumplí el plazo en el que debía haber entregado este trabajo que vencía a finales de 2019. No obstante, cuando Óscar Alzaga Villaamil con toda amabilidad me preguntó, a instancias de la revista, en junio de 2020 si podría entregar el texto a la vuelta del verano, le dije que lo intentaría. Y he podido terminarlo.

\section{EL BOLETIIN EN CIFRAS Y DATOS}

Entre noviembre de 1954 y octubre de 1964 se publicó el Boletín Informativo del Seminario de Derecho Político de la Universidad de Salamanca. Fueron en total 32 números los que vieron la luz, aunque varios de ellos agrupados en un solo volumen, por lo que fueron veinte. El primero era un folleto, sin índice, de 23 páginas, con cinco reseñas bibliográficas, firmadas dos por Enrique Tierno Galván y una cada uno por Pablo Lucas Verdú, Fernando Gil Nieto y Jesús de la Cueva, estos dos últimos profesores ayudantes. Incluía la «Oración fúnebre de Pericles», recogida por Tucídides y traducida por el catedrático de Griego Jesús Lérida Domínguez, que también aportará la traducción de textos griegos publicados en algunos números posteriores, y terminaba con una recomendación de lectura de varias revistas y la petición de que los libros y la correspondencia se dirigieran a Pablo Lucas Verdú. En la contraportada llevaba, como todos los demás números lo llevarían después, el gran sello de la Universidad de Salamanca.

Ya en 1955, en el número correspondiente a los meses de enero y febrero, se adopta la estructura básica que se mantendrá hasta el final: artículos, recensiones, índice de revistas, textos y libros recibidos. Era todavía un folleto que solamente incluía un artículo - el de Carl Schmitt, «Apropiación, partición, apacentamiento»- y llegaba a las 39 páginas. Advertía que el Boletín «estaba controlado y dirigido por la Cátedra de Derecho Político, cuyo titular es, don Enrique Tierno Galván» y seguía diciendo que la correspondencia y los libros se enviaran al Profesor Adjunto, doctor Pablo Lucas Verdú. Su precio era de 10 pesetas.

Con el tiempo se irán añadiendo algunas secciones nuevas. Es el caso de Europa a la vista que aparece en el n. ${ }^{\circ} 8-9$ de enero-abril de 1956. Morodo ${ }^{6}$ explica que ese era el nombre de una publicación anterior por él dirigida, pensada para preparar la Asociación Española por la Unidad Funcional de Europa, creada a instancias de Tierno en 1955, publicación que solamente editó tres o cuatro

5 En https://www.boe.es/biblioteca_juridica/index.php?tipo=R\&modo=2.

6 Morodo, R., Atando cabos, cit, p. 154. 
números de pocas páginas. En ese mismo número 8-9/1956 del Boletín se incluyen estas otras secciones: Notas y Trabajos de Seminario. En el n. ${ }^{\circ}$ 29/30 de 1963 se incorpora la de Perfiles, que se mantendrá en los dos últimos números. Los publicados serán: «Perfil de un laborista», «Pietro Nenni y Giuseppe Saragat» y «Harold Wilson», todos ellos, obra de José Blasco.

Aunque no siempre se reflejaban en las portadas, sí se publicaron en el Boletín diversas encuestas. Así, en los n. ${ }^{\circ}$ 3, 4 y 6 aparece una sobre «El impacto religioso en la sociedad laica salmantina». En el n. ${ }^{\circ} 5$ figura un «Análisis de algunos grupos universitarios hispanoamericanos en Salamanca» por Juan José Borja Nathan. Y en el n. ${ }^{\circ} 6$ se publica otra sobre «El status social de las sirvientas domésticas en Salamanca». El n. ${ }^{\circ}$ 10-12/1956 recoge una «Encuesta acerca de la mentalidad prenupcial de los universitarios salmantinos». En el n. ${ }^{\circ}$ 16/19 está la encuesta «Generalidades sobre el nivel de vida del estudiante salmantino» y el n. ${ }^{\circ} 20 / 23$ publica otra sobre el «Movimiento migratorio de obreros agrícolas en la provincia de Salamanca». Por su parte, el n. 31 incluye una «Encuesta sobre la vida militar», de Víctor Pérez Díaz.

A partir del correspondiente a marzo-abril de 1955, el Boletín empieza a numerarse, es el n..$^{\circ} 3$ y con sus 93 páginas ya no es un folleto. En el n. ${ }^{\circ} 7$, el último de 1955, correspondiente a noviembre y diciembre de ese año, se hace constar el equipo directivo: Enrique Tierno Galván, director; Pablo Lucas Verdú, subdirector; y Luis Ortega Herráiz, secretario de redacción a quien sustituirá a partir del n. ${ }^{\circ}$ 10/12, correspondiente a mayo-octubre de 1956, Raúl Morodo Leoncio y ya permanecerá invariable, salvo en lo relativo al encargado de la correspondencia que pasó a ser Ángel de Juan a partir del n. ${ }^{\circ}$ 24, de marzo de 1958 a septiembre de 1959. Entre los jóvenes colaboradores que les ayudaron e, incluso, escribieron en el Boletín Morodo ${ }^{7}$ recuerda a Fermín Solana Prellezo, Pedro de Vega García, Manuel Andrino Hernández, Federico Chiriboga, Jacinto Garaycoa y Rafael Garzaro. Todos publicaron en el Boletín ya sea artículos, notas, traducciones o recensiones.

La tirada inicial, según Raúl Morodo ${ }^{8}$ fue de setecientos ejemplares, aunque, después, se aumentó. La periodicidad bimensual solamente se mantendrá en 1955. En 1956 se publicarán tres volúmenes con dos números cada uno. Y desde 1957 no hay una regularidad fija ni respecto de las fechas ni de los números que se unen en un solo volumen. Alcanzan los publicados más de trescientas páginas. La factura artesanal ${ }^{9}$ será otra característica que se mantendrá hasta el final y explica que no siempre haya un índice, no se indique, en general, la condición del colaborador y que, incluso, haya alguna aportación sin firma o firmada con iniciales y no haya sido posible identificar a su autor.

7 Morodo, R., «Enrique Tierno: semblanza, aventura y compromiso», en Sistema, n. ${ }^{\circ}$ 71-72/1986. Monográfico sobre Enrique Tierno Galván. El hombre, el intelectual y el político, p. 11 y Atando Cabos, cit. p. 149.

8 Morodo, R., Atando cabos, cit. p. 147.

9 Morodo, R., Atando cabos, cit. p. 148 
Aunque Raúl Morodo ${ }^{10}$ recuerda que la edición se regalaba o se utilizaban los ejemplares para obtener por intercambio revistas nacionales y extranjeras, se irá incrementando el precio. A 20 pesetas el n. ${ }^{\circ}$ 8-9 de enero-abril de 1956; a 30 pesetas el n. ${ }^{\circ} 10-12$, de mayo-octubre; a 40 pesetas el n. ${ }^{\circ} 13-15$ de enero-abril de 1957; 50 pesetas el de mayo octubre; a 50 pesetas el n. ${ }^{\circ} 16-19$ de mayo octubre de 1957; a 60 pesetas el n. ${ }^{\circ} 20-23$ de enero-febrero de 1958; a 75 pesetas el n. ${ }^{\circ} 24$ de marzo de 1958 a septiembre de 1959; a 85 pesetas el n. ${ }^{\circ} 25$ de octubre de 1960; bajará a 60 pesetas o 1 dólar los n. ${ }^{\circ} 26$ de marzo de 1962 y 27 de agosto de 1962 y ya quedará en 100 pesetas en los números restantes: 28, 29-30, 31 y 32.

Entre el n. ${ }^{\circ} 25$ de octubre de 1960 y el n. ${ }^{\circ} 26$ de octubre de 1962 hay un paréntesis. En aquél se incluía una addenda mecanografiada, de la que yo no dispongo, pero sí obra en el ejemplar que conserva la Biblioteca del Centro de Estudios Políticos y Constitucionales, en la que se explicaba que sería el último «debido a la suspensión en sus funciones docentes del director de la publicación D. Enrique Tierno Galván». No obstante, una vez en Estados Unidos, adonde marchó entonces, Tierno logró continuarla. Aunque se imprimieron en Nueva York, aparecen publicados en Princeton, Nueva Jersey, en cuya Universidad enseñó en 1962 , los n. ${ }^{\circ} 26$ y 27 , que se presentan como «2. ${ }^{a}$ Época», al igual que todos los sucesivos, impresos otra vez en Salamanca a su regreso. Por eso, el precio de esos dos números se expresa también en «1 dólar o su equivalente en cualquier otra moneda». Y en sus páginas se encuentran anuncios infrecuentes en publicaciones académicas. En efecto, en la página 22 del n. ${ }^{\circ} 26$ y en la página 26 del n. ${ }^{\circ}$ 27, hay publicidad de F. López. Construction Co., Inc. Concrete Contractors. La razón no es otra que el Boletín se pudo publicar «bajo los auspicios de la Asociación de Universitarios Españoles en América, sostenido económicamente por don Francisco López, Silver Springs, Maryland», tal como se hacía constar.

El propio Tierno Galván ${ }^{11}$ se refiere a él como «el mecenas que nos dio los mil dólares» que hicieron posible la publicación y le dedica este recuerdo: «Se llamaba Francisco López y había salido subrepticiamente de Galicia como emigrante, alcanzando el barco a nado. Con singular denuedo se convirtió en un constructor de gran importancia en el Estado de Maryland y según ocurre siempre o casi siempre con los gallegos, ni perdió el acento, ni el buen humor, ni la lealtad a su tierra, ni el amor creciente y entrañable a quienes consideraba sus amigos. Nos ayudó sin pedir nada. Cuando murió atravesando el Atlántico en una avioneta sentimos todos sus amigos españoles el dolor mezclado con el asombro de comprobar que la generosidad es tan frágil como la vida del generoso, persistiendo el recuerdo de lo que nos ayudó y de lo que pudimos hacer con su ayuda».

La obtención de ayudas económicas de fuentes singulares para la publicación del Boletín no fue, sin embargo, una novedad, ya que, según recuerda Raúl

10 Morodo, R., Atando cabos, cit. p. 149.

11 Tierno Galván, E., en Cabos Sueltos. Bruguera, Barcelona, 1981, p. 268. 
Morodo $^{12}$, la financiación corría a cuenta del presupuesto para compra de libros y lo completaba Tierno de su bolsillo. De su capacidad para lograr aportaciones dan fe otros anuncios publicados en números anteriores y en alguno posterior, impresos en Salamanca. Ya en el n. ${ }^{\circ} 4$ se recoge el de El lector costarricense. Editorial San José. El de SIFEMA, S.A. Fundición de Acero Moldeado al Horno Eléctrico y Talleres Mecánicos, de Bilbao, se encuentra en la p. 149 del n. ${ }^{\circ} 7$, en la 193 del n. ${ }^{\circ} 16 / 19$ y en la 328 del n. ${ }^{\circ} 20 / 23$. En el n. ${ }^{\circ} 7 / 1955$ y en el n. ${ }^{\circ} 8-9 / 1956$ aparece el anuncio de la Librería Pueyo y Editorial Pueyo, S. A. en las págs. 145 y 240, respectivamente. En los n. ${ }^{\circ} 10-12 / 1956$ y 13-15/1957, págs. 144 y 278, respectivamente, hay publicidad de la Línea Aeropostal Venezolana. Y en las págs. 228 del primero de ellos, 207 del n. ${ }^{\circ}$ 16-19/1957, y 215 del n. ${ }^{\circ} 20-23$ se anuncia la empresa bilbaína Carbometal, S.A. Sucesores de Astoreca, Azqueta y Cía. Igualmente, C.E.L. Club Escuela de Lenguas, de Madrid se anuncia en la p. 295 del n. ${ }^{\circ} 25^{13}$.

El último número del Boletín, el 32, lleva la fecha de octubre de 1964. En 1965 Enrique Tierno Galván fue separado definitivamente de su cátedra de Salamanca por acuerdo del Consejo de Ministros de 13 de agosto de 1965. Le sancionó así por participar en una asamblea no autorizada celebrada el 25 de febrero de 1965 en la Facultad de Filosofía y Letras de la Ciudad Universitaria de Madrid convocada en el marco de las protestas contra el Sindicato Español Universitario. Según la sentencia de la Sala Quinta del Tribunal Supremo de 3 de julio de $1967^{14}$, desestimatoria de su recurso contencioso-administrativo, los hechos que la justificaban eran, además de la participación en dicha asamblea, «hacer entrega de unas cartas dirigidas a otros dos Catedráticos de adhesión a la actitud de insubordinación en que se había colocado el elemento escolar en fechas anteriores» y, también, que en esa asamblea «se aprobaron los siguientes acuerdos: Declarar la huelga de todos los escolares, impedir a los Catedráticos el ejercicio de la función docente; adherirse a la postura de rebeldía de los estudiantes portugueses contra las autoridades de aquél país, y gestionar la solidaridad a estos acuerdos de los estudiantes de otros centros docentes de la nación».

Es conocido que los demás catedráticos separados — se expedientó y sancionó a más, entre ellos a Santiago Montero Díaz, catedrático de Historia de la Filosofía Antigua, y a Mariano Aguilar Navarro, catedrático de Derecho Internacional, ambos de la Universidad de Madrid, suspendidos por dos años- por participar en esa asamblea fueron José Luis López Aranguren, catedrático de Ética, y Agustín García Calvo, catedrático de Filología Latina. Y que José María Valverde Pacheco, ante esa decisión gubernamental, renunció a su cátedra de Estética de la Universidad de Barcelona, porque, según escribió a José Luis López Aranguren, nulla aesthetica sine ethica. Tierno Galván se refiere a él, así como a Antonio Tovar

12 Morodo, R., Atando cabos, cit. p. 147.

13 De las dificultades de financiación da cuenta la tesis doctoral de S. GonZÁlez GómEz, La Universidad de Salamanca durante el franquismo, vol. II. Universidad de Salamanca, 2013, pp. 581 y sigs.

14 Accesible en www.poderjudicial.es con la referencia ECLI:ES:TS:1967:3877. 
Llorente, catedrático de Latín y rector que fue de la Universidad de Salamanca, que pidió la excedencia, y a Federico Gaeta, catedrático de Matemáticas de la Universidad de Zaragoza, que marchó al extranjero ${ }^{15}$.

Cuenta Carlos Ollero ${ }^{16}$ que, siendo «ya prácticamente imposible para Enrique Tierno continuar en Salamanca el Boletín que editaba su cátedra» por la persecución que desvertebró su actividad intelectual y política, comenzó a publicarse en 1971 el Boletín Informativo de Ciencia Política en la Facultad de Ciencias Políticas y Sociología, con Raúl Morodo de secretario. Ollero dice que en la presentación de su n. ${ }^{\circ} 1$ designó esta nueva revista como continuadora del salmantino. Y Lucas Verdú ${ }^{17}$ confirma ese propósito de continuidad.

No quedaría completa esta reseña sin dejar constancia de que, años más tarde, en octubre de 1978, Raúl Morodo, a la sazón catedrático de Derecho Político en la Universidad Nacional de Educación a Distancia, fundó y dirigió el Boletín Informativo del Departamento de Derecho Político. Es fácil ver la huella de la experiencia salmantina en el título de esta nueva revista académica.

A partir de su n. ${ }^{\circ} 4$, de 1979, ya dirigida por Óscar Alzaga Villaamil, pasó a llamarse Revista del Departamento de Derecho Político y, desde 1981, Revista de Derecho Político. Alzaga explicó ${ }^{18}$ el abandono de la denominación inicial porque Boletín Informativo era un rótulo «bien modesto» una vez asentada «la pequeña aventura intelectual» en que consiste la revista. Y el nombre definitivo, decía, más breve, respondía al «abierto talante» con que él y sus colaboradores concebían la revista. Presentarla como de un Departamento, precisaba, podía «parecer reivindicación de propiedad de un determinado equipo docente y nada hay más lejos de nuestra intención». De ahí que a fin de «evitar, en consecuencia todo peligro de concepción de la revista como un club cerrado hemos revisado el título».

Al día de hoy se han publicado ya 107 números de la Revista de Derecho Político, dirigida desde su n. ${ }^{\circ}$ 26, de octubre de 1986, por Antonio Torres del Moral.

\section{EL ESPÍRITU DEL BOLETÍN}

Explica Tierno Galván ${ }^{19}$ el objetivo al que aspiraba con la publicación del Boletín. Recuerda, en efecto, que su actividad académica en Salamanca rebasaba

15 Tierno Galván, E., Cabos sueltos, cit. pp. 339 y sigs.

16 Ollero Gómez, C., «La «idea» de la obra de Tierno y su tensión dialéctica», en Sistema, n. ${ }^{\circ} 71-72 / 1986$, cit. p. 45

17 Lucas Verdú, P., «La teoría constitucional del profesor Tierno Galván», en Sistema n. ${ }^{\circ}$ 71-72/1986, cit. p. 67 .

18 Alzaga Villaamil, O., «El cambio de nombre de la revista. La razón de ser de un número monográfico y algunas breves divagaciones». Revista de Derecho Político, n. ${ }^{\circ} 8 / 1981$, pp. 5 y 6.

19 Tierno Galván, E., Cabos sueltos, cit., pp. 198 y sigs. 
con mucho los límites de su disciplina. Dice que en sus seminarios y, luego, en el Boletín, «hacía incursiones por casi todos los ámbitos del saber a mi alcance» y que así «iba formando alrededor de la cátedra un conjunto de adictos (...) que aceptaban o rechazaban teorías que corrían por Europa, pero que en España aún no habían sido recibidas por la mayoría de los universitarios». Añade que «allí surgió uno de los primeros esfuerzos sistemáticos y públicos en favor de una Europa organizada de manera que no excluyese en el orden político a España». Señala que en ese marco «nacieron los primeros intentos (...) acerca de la nueva lógica formal y sus relaciones con las matemáticas» y que «la cátedra de Derecho Político fue, en cierto modo, el impulso permanente y el Boletín del seminario sirvió de brújula y de orientación a ensayos parecidos en otros lugares».

Raúl Morodo, se extenderá más ${ }^{20}$. Tras describir antes el ambiente del Seminario de Derecho Político y referirse a quienes participaban en él, explica que el Boletín, «con intención consciente cumplía o quería cumplir varios objetivos: en primer lugar, cohesionando y formalizando un grupo amplio, ni endogámico, ni unidimensional, aunque académico, y como plataforma muy amplia y diversa; en segundo lugar, hacer conocer, con traducciones de artículos, autores de corrientes ideológicamente avanzadas; y, en tercer lugar, ir aglutinando a profesores, profesionales y, en general, jóvenes intelectuales de distintas regiones españolas». En otras palabras, prosigue, «con un fondo académico y universitario, de análisis y crítica, iniciar la debelación de la dominante cultura autoritaria e ir asentando una nueva cultura democrática». Dice, también, que tal vez «la función más importante que realizó el Boletín fue la introducir en el mundo académico y escolástico mortecino de entonces - lo que Tierno llamaba «cultura de hibernación»- autores europeos y americanos que representaban novedad y modernidad». Apunta que «actuará de revulsivo intelectual y divulgador de la cultura europea clásica (de los griegos a Hegel y a Marx: existencialismo (Sartre), neopositivismo (Wittgenstein) (...), el funcionalismo americano (Parsons), el socialismo marxista o humanista (Bloch, Mannheim, Myrdal, Lukács, Gramsci). También el cristianismo progresista». Y aventura que «cuando se lleve a cabo un estudio del Boletín —y en el siglo XxI, que será largo, alguien lo hará- se podrá percibir su talante pionero frente a la cultura oficialista dominante: tomismo, integrismo, tradicionalismo».

Algo parecido resalta apoyándose en Elías Díaz — que colaboró en el Boletín-y en Morodo, Jorge Novella Suárez ${ }^{21}$. Dice que la publicación del Boletín Informativo introduce «una investigación científico-social apoyada sobre datos empíricos y la consiguiente constitución, con suficiente rigor y autonomía, de una sociología entendida como auténtica ciencia, extendiendo su radio de acción

20 Morodo, R., Atando cabos, cit., pp. 148 y sigs.

21 Novella SuÁrez, J., El proyecto ilustrado de Enrique Tierno Galván. Biografía intelectual y política. CEPC, Madrid, 2001, p. 129. 
a la ciencia política, jurídica, económica, etc., así como el positivismo lógico y la filosofía analítica, se traducen por primera vez textos marxistas de Lukács, Escuela de Frankfurt, así como otros de Hegel Bertold Brecht, Krasinski, se publican artículos sobre Saint Simon, Cossío, Erasmo, Wittgenstein o «Democracia y revolución en la URSS». Todo un elenco de autores, problemas y cuestiones de diversa índole que contribuyen a renovar y dinamizar el adocenado panorama cultural español».

Lucas Verdú subrayaráa ${ }^{22}$ que una de las preocupaciones compartidas por el círculo interno del Seminario de Salamanca, reflejada en el Boletín, era el Estado de Derecho y que en su seno se insistió sobre la regularidad jurídica, el resguardo de los derechos y la limitación del poder. En este punto destaca el influjo de esta orientación en Elías Díaz. Habla también de la «siembra constitucionalista» de Tierno Galván, en la que ve no sólo una intención culturalista y didáctica, sino también otra de tipo político «en la medida en que la exposición de los principios de la cultura política demoliberal, era un método que servía para resaltar el contraste con las instituciones y los hábitos autocráticos del régimen franquista y de las dictaduras iberoamericanas». Y deja constancia de los resultados positivos logrados respecto de los que cita su propia concepción del Derecho Constitucional, las aportaciones de Raúl Morodo, de Manuel Andrino Hernández y de Pedro de Vega García.

Desde una perspectiva académica diferente, Manuel Tuñón de Lara dirá ${ }^{23}$ del Boletín que fue «una rara tribuna de libre expresión y de alta calidad intelectual» y que pocas veces había sentido «la especial satisfacción de escribir para algo en que «se está a gusto» y en que te encuentras en las mejores compañías». Y Salvador Giner ${ }^{24}$ recordará que Tierno Galván le publicó «el primer ensayo medianamente decente de los que he escrito» en el Boletín salmantino «de ya legendaria memoria». Se refiere a su artículo «Comentarios liminares sobre la llamada sociedad de masas», publicado en el n. ${ }^{\circ}$ 28/1963.

Por su parte, Xavier Tusell ${ }^{25}$ destacó que el Boletín, además, de convertirse en «un instrumento de protesta política e incluso un órgano de un grupo que ya pretendía tener una cierta vocación de partido», desde el punto de vista intelectual «jugó un papel muy importante como introductor en España de novedades intelectuales o filosóficas que iban desde Brecht a Lukács» y desempeñó «una amplia labor europeísta». Y en el mismo sentido, al compararlo con otras publicaciones sobre ciencias sociales de la época ${ }^{26}$, se ha observado que el Boletín, cuyo

22 Lucas Verdú, P., «La teoría constitucional del profesor Tierno Galván», cit. pp. 64 y sigs.

23 Tuñón De Lara, M., «Enrique Tierno en el recuerdo», en Sistema, n. ${ }^{\circ}$ 71-72/1986, cit., pp. $183-184$

24 Giner, S., «Memorias de don Enrique Tierno», ibidem, p. 198.

25 Tusell, X., La oposición democrática al franquismo. Planeta, Barcelona, 1977, p. 355.

26 Pecourt, J., «El campo de las revistas políticas bajo el franquismo», en Papers, n. ${ }^{\circ}$ 81/2006, pp. 215 y sigs. 
contenido era decidido por su equipo de dirección «sin la interferencia de aparatos eclesiásticos o burocráticos», gozaba de una autonomía de la que las demás carecían aunque tuviera que enfrentarse a la censura externa. Y se ha insistido en que articuló un espacio de discusión en el que se introdujo una metodología científica inspirada por el positivismo lógico que ayudó a incrementar el rigor y la objetividad de la investigación social y del análisis político ${ }^{27}$.

\section{EL BOLETÍN POR DENTRO}

Los artículos, las notas y las recensiones publicados en el Boletín abordaron cuestiones de Ciencia Política, Derecho Constitucional, Filosofía del Derecho, Derecho Internacional, Derecho Penal, Sociología, Economía, Filosofía, Psicología, Historia, Literatura, Arte. Entre sus autores, se cuentan destacados intelectuales españoles y extranjeros. Los primeros reúnen a figuras consagradas de prestigio indiscutido y jóvenes universitarios que más tarde serán maestros reconocidos en distintas disciplinas académicas. Basta con repasar los índices para comprobarlo y el hecho de que quisieran participar en los trabajos del Seminario de Derecho Político y colaborar en su Boletín quienes después serán figuras relevantes en la Universidad y en la vida política españolas es la mejor prueba del impacto que produjo la orientación que Tierno Galván y sus jóvenes colaboradores imprimieron al Seminario y al Boletín. Acredita, en efecto, el reconocimiento por todos ellos, del interés y, sobre todo, de la novedad que suponían en el clima académico salmantino y español de entonces. Por otro lado, no se debe desconocer la capacidad atractiva de la personalidad de Tierno sobre quienes le trataron en Murcia, Salamanca o Madrid. Es un factor añadido que explica la presencia en sus páginas de autores de sus Universidades.

No se debe olvidar que cuando aparece el Boletín y durante la mayor parte de su existencia (1954-1964) el Régimen no había perdido sus aristas más duras. No había comenzado aún el proceso de revestimiento de una apariencia de legalidad culminado con la Ley Orgánica del Estado en 1967. Ni siquiera se había aprobado la Ley de Orden Público, ni creado el Tribunal de Orden Público que se encargaría a partir de 1963 de perseguir la disidencia política y sindical o la Ley de Prensa que en 1966 suprimió la censura previa a cambio de limitar la libertad de información mediante un amplísimo catálogo de excepciones cuya transgresión se sancionaba y eran, en realidad, la regla. Permanecía, pues, todo el aparato represor surgido de la Guerra Civil respecto del que esas Leyes y ese Tribunal vinieron a ser males menores. La concentración de todos los poderes en Franco, único titular de la potestad legislativa hasta 1967, año en que, en virtud de la Ley Orgánica del Estado pasó a compartirla con las Cortes Españolas, expresa mejor que nada la situación.

27 Ibidem.

UNED. Teoría y Realidad Constitucional, núm. 46, 2020, ISSN 1139-5583, pp. 587-611 
Pues bien, del simple repaso de los índices de los números publicados, se pueden extraer con facilidad varias observaciones.

\section{El primer artículo y los últimos}

Ya se ha dicho que el que debe considerarse primer número del Boletín era un folleto con unas pocas recensiones y la «Oración fúnebre de Pericles» y que, en el segundo, ya en los primeros meses de 1955, se publica el primer artículo. En realidad, es el único porque el resto son recensiones y la traducción de las «Conversaciones entre los Atenienses y los Melios», de Tucídides. Es de Carl Schmitt y se trata de «Apropiación, partición, apacentamiento», texto traducido por Antonio Truyol Serra. No es extraña la elección. Sobre Carl Schmitt nada es preciso decir por ser notorias su talla intelectual y su obra. Tierno Galván y Truyol Serra, colegas y amigos, tuvieron la ocasión de conversar detenidamente con él en Murcia y en Madrid. Ambos evocan esa relación y dejan clara la impresión que les produjo $^{28}$, sobre todo a Tierno, que reconoce que sus conversaciones con Schmitt le obligaron a repensar las ideas admitidas y a preocuparse por encontrar fundamentos sólidos para las nuevas ${ }^{29}$

Las circunstancias harán que casi diez años después, el primer artículo del último número, el 32, de octubre de 1964, fuera también de un filósofo alemán, Günther Rohrmoser, «La teoría del Estado en Hegel y el problema de la libertad en la sociedad contemporánea». Y que, al igual que Schmitt, fuera un exponente del pensamiento conservador y, además, crítico de la Escuela de Frankfurt. Ahora bien, es interesante reparar en el contenido de ese n. ${ }^{\circ} 32$. Contiene también estos otros artículos: de Richard Hauser, «Las trayectorias de la paz»; de José Luis Fernández de Castillejo, «De Velázquez a Tapies»; de Enrique Tierno Galván, «Diderot como pretexto»; de W.J. Callahan, «Conflictos laborales en el siglo XVIII»; de Pablo Lucas Verdú, «En torno al problema conceptual del Derecho Político»; de Jorge Enjuto, «La filosofía de Alfred North Whitehead»; y de Manuel Medina Ortega, «El derecho de asilo diplomático en España». Y en la sección de Europa a la vista incluye los artículos de Ralph Miliband, «Programa de una política laborista»; y de Gilles Martinet, «El porvenir del gaullismo». Luego, en la sección de Notas, publica las de Manuel Tuñón de Lara, «1929: el último año de la Dictadura»; de José Luis Abellán, «Ortega y el aristocraticismo burgués»; de Ángel de Juan, «Acotaciones al tema del intelectual»; de Gabriel Tortella, «Reflexiones en torno al imperialismo norteamericano en 1898»; de Ignacio Sotelo, «Sartre y el marxismo»; de Ramón Lugrís, «El anti-intelectualismo en los Estados Unidos»; de Julián Marcos, «Lo que

28 Tierno Galván, E., en Cabos sueltos cit. pp. 166 y sigs.; y Truyol Serra, A., en «Enrique Tierno, Carl Schmitt y Benito Cereno», Sistema, n. ${ }^{\circ} 71-72 / 1986$, cit. pp. 69 y sigs.

29 Tierno Galván, E., Cabos sueltos, cit. p. 167. 
el cine español podría ser»; de Alfredo Calonge, «Henry Lévy-Bruhl»; y de Juan Alfonso Ortí, «En torno a una fenomenología del fascismo».

Ese contenido es una buena muestra de la talla de los autores, del sentido enciclopédico del Boletín, el propio del Derecho Político, y de la pluralidad de orientaciones a las que se abría ${ }^{30}$. Igualmente, muestra su sensibilidad por los problemas permanentes y por las cuestiones de la actualidad. Seguidamente podremos comprobar que esa fue la tónica observada en toda su trayectoria.

\section{La contribución del equipo directivo y de sus jóvenes colaboradores}

Tierno Galván y Lucas Verdú escribieron tres de las cinco recensiones del primer número. En los sucesivos, Tierno Galván, Lucas Verdú y Morodo serán asiduos autores.

Así, Tierno publicará entre artículos y notas los siguientes trabajos: «Charlot y el origen social de lo cómico» (n. $\left.{ }^{\circ} 4 / 1955\right)$; «XII Tesis sobre el funcionalismo europeo» (n. $\left.{ }^{\circ} 7 / 1955\right)$; «Notas sobre la tertulia» y «H. Rommen y el Estado en el pensamiento católico» (n. $\left.{ }^{\circ} 8-9 / 1956\right)$; «Teatro y novela en la cultura de hibernación» (n. $\left.{ }^{\circ} 10-12 / 1956\right)$; «La realidad como resultado» y «Federalismo y funcionalismo europeo» (n. $\left.{ }^{\circ} 13-15 / 1956\right)$; «De las comunidades o la historia como proceso» (n. $\left.{ }^{\circ} 16-19 / 1957\right)$; «Erotismo y trivialización» (n. $\left.{ }^{\circ} 20-23 / 1958\right) ; ~ «$ Es el «Lazarillo» un libro comunero?» (n. $\left.{ }^{\circ} 20-23 / 1957-1958\right)$; «Ambigüedad y semidesarrollo» (n. ${ }^{\circ}$ 25/1960); «Los sustitutivos del entusiasmo» (n. ${ }^{\circ}$ 26/1962); «Anatomía de la conspiración» (n. ${ }^{\circ}$ 27/1962); «Humanismo y sociedad» (n. $\left.{ }^{\circ} 29-30 / 1963\right)$; «Diderot como pretexto» (n. $\left.{ }^{\circ} 32 / 1964\right)$.

Las contribuciones de Lucas Verdú serán: «El problema de los cambios de la Constitución» (n. $\left.{ }^{\circ} 4 / 1955\right)$; «Consideraciones en torno al concepto, método y funciones del Derecho constitucional comparado» (n. $\left.{ }^{\circ} 6 / 1955\right)$; «La repercusión de los

30 De entre los estudios dedicados al carácter enciclopédico de la disciplina, recordaré ahora el artículo que P. Lucas Verdú escribió en el n. ${ }^{\circ}$ 32/1964 del propio Boletín — «En torno al problema conceptual del Derecho Político»-y, posteriormente, su Curso de Derecho Político, vol I. cit., pp. 152 y sigs. Son ilustrativas al respecto las consideraciones de O. Alzaga Villaamil, «En torno a un posible nuevo enfoque de la asignatura Derecho Político», en Revista del Departamento de Derecho Político, n. ${ }^{\circ}$ 4/1979, pp. 7 y sigs. Además, C. Ollero, «Derecho Político, Ciencia Política, Derecho Constitucional» y A. Torres Del Moral, «El concepto de Derecho Político en la obra de Lucas Verdú», ambos en el n. ${ }^{\circ} 11-12 / 1984$ de la Revista de Política Comparada, pp. 35 y sigs. Recientemente, J. GARCía FERnÁndez ha recogido en sus Estudios de Historia del Derecho Público. Reus, Madrid, 2019, pp. 179 y sigs., dos interesantes trabajos en los que refleja sentido que tuvo el Derecho Político y la transición desde él al Derecho Constitucional. El primero es el artículo publicado en el n. ${ }^{\circ}$ 174/2016 de la Revista de Estudios Políticos, «Pablo Lucas Verdú: un jurista entre dos generaciones del Derecho Político Español», que desarrolla las ideas expuestas en G. De VergotTini, Giornata di Studi in memoria di Pablo Lucas Verdú. Accademia delle Scienze dell Istituto di Bologna. Bononia University Press, Bolonia, 2015. Y el segundo es el capítulo ampliado de la obra dirigida por B. Pendés, La España Constitucional (1978-2018). Trayectoria y perspectivas. CEPC, Madrid 2018, titulado «Cuarenta años de Derecho Constitucional en España: del Derecho Político al Derecho Constitucional». 
cambios sociales en las Constituciones rígidas» (n. ${ }^{\circ}$ 10-12/1956); «La historia de las ideas políticas y su función en el ámbito del Derecho Político» y «Sobre el régimen político de la URSS» (n. $\left.{ }^{\circ} 13-15 / 1956\right)$; «Problemática actual de la Justicia constitucional y del examen de constitucionalidad de las leyes» (n. ${ }^{\circ} 16-19 / 1957$ ); «La interpretación constitucional» (n. $\left.{ }^{\circ} 20-23 / 1957\right)$; «Crisis del lenguaje y lenguaje de la Iglesia» (n. ${ }^{\circ}$ 25/1960); «Tocqueville y la democracia liberal» (n. ${ }^{\circ}$ 26/1962); «Ideologías, instituciones y sistemas político-sociales europeos» (n. ${ }^{\circ}$ 28/1963); «En torno al problema conceptual del Derecho Político» (n. 32/1964).

Por su parte, Raúl Morodo publicará: «Revolución y contrarrevolución en España» (n. ${ }^{0}$ 7/1955); «El funcionalismo ante la crisis de Europa» (n. ${ }^{\circ}$ 10-12/1956); «El proyecto de Convención de los derechos sociales y económicos del Consejo de Europa» (n. ${ }^{\circ}$ 16-19/1957); «La integración política europea: el Consejo de Europa» (n. ${ }^{\circ}$ 20-23/1957); «Constitución, legalidad, legitimidad» (n. ${ }^{\circ}$ 26/1962); «La reforma constitucional en Jovellanos y Martínez Marina (n. ${ }^{\circ} 29-30 / 1963$ ); «Notas sobre el derecho de petición» (n. $\left.{ }^{\circ} 31 / 1964\right)$.

Está claro que los tres fueron avanzando en las páginas del Boletín trabajos que luego proseguirán o incluirán en sus obras posteriores.

Los colaboradores que frecuentaban el Seminario y ayudaban al equipo directivo escribieron también en el Boletín. De los mencionados por Raúl Morodo nos encontramos con las siguientes contribuciones entre los artículos y las notas.

Manuel Andrino Hernández escribió en el n. ${ }^{\circ}$ 4/1955 («El federalismo de Evaristo Ventosa»); en el n. ${ }^{\circ} 7 / 1955$ («El federalismo de Evaristo Ventosa II); en el n. ${ }^{\circ}$ 8-9/1956 («Algunos aspectos de sociología rural: los romances de ciego»); en el n. ${ }^{\circ}$ 10-12/1956 ( «Sobre las reformas constitucionales»); en el n. ${ }^{\circ}$ 16-19/1957 («Derecho y situación»); en el n. ${ }^{\circ}$ 24/1959 ( «Teoría militante del Derecho»); y en el n. ${ }^{\circ}$ 25/1960 ( Sociedad y familia en la elección matrimonial»). Fermín Solana Prellezo lo hizo en el n. $24 / 1959$ [ «Introducción a los cambios políticos (Esquema general de la revolución y sus homólogos)]; Federico Chiriboga en el n. ${ }^{\circ}$ 16-19/1957 («Aspectos funcionales del grupo humano»); Rafael Garzaro en el n. ${ }^{\circ} 20-23 / 1958$ ( «Sobre la reducción del socialismo a técnica») y Pedro de Vega lo hará en el n. ${ }^{\circ} 29-30 / 1963$ («En torno a la paz y algunas de las dificultades que obstaculizan su proceso»).

Angel de Juan, por su parte, participó en el n. 25/1960 («Ideología y utopía en Mannheim») y en el n. ${ }^{\circ}$ 32/1964 («Acotaciones al tema del intelectual») y el primer secretario de redacción, Luis Ortega Herráiz, escribió en el n. ${ }^{\text {3 3/1955 }}$ («La enseñanza de las ciencias sociales en Francia»).

\section{La variada procedencia intelectual de los autores que colaboran en el Boletín y la diversidad de temas tratados}

Si nos fijamos, en primer lugar, en los autores españoles que publicaron en las páginas del Boletín artículos, notas o encuestas, podremos comprobar que 
conviven en ellas autores entonces en plena madurez y de autoridad intelectual reconocida con otros, jóvenes en aquél momento, que años después serán referentes indiscutidos. Y también es posible apreciar la pluralidad de especialidades a las que pertenecían.

Empezando por quienes se adscribían a la de Derecho Político, es significativo que publicaran antiguos catedráticos de la disciplina: Carlos Ruiz del Castillo, en n. ${ }^{\circ}$ 5/1955 ( «La personalidad humana en su aspecto jurídico»), Nicolás Pérez Serrano, en el n. ${ }^{0} 7 / 1955$ ( «El problema de la "desconstitucionalización”») y Francisco Ayala, en el n. ${ }^{\circ}$ 29-30/1963 ( «La Filosofía política y la situación cultural presente»), además del propio Enrique Tierno Galván. También destaca que hicieran sus primeras armas en el Boletín los que lo irían siendo después. Además de Pablo Lucas Verdú y de Raúl Morodo, es el caso de Pedro de Vega, que participó en el n. ${ }^{\circ}$ 29-30/1963 ( «En torno a la paz y a algunas dificultades que obstaculizan su proceso»), al que ya se ha hecho referencia. Asimismo, el de Gumersindo Trujillo, que colaboró en el n. ${ }^{\circ}$ 26/1962 («Pi y Margall y los orígenes del federalismo español») y de Miguel Martínez Cuadrado en el n. ${ }^{\circ}$ 28/1963 («Las limitaciones de un plan indicativo: el IV Plan francés de desarrollo económico y social y las notas del I Plan español»). Otros profesores de Derecho Político que colaboraron con el Boletín fueron Ramón Sáinz de Baranda que escribió en el n. ${ }^{\circ} 16-19 / 1957$ ( «Las comunidades especializadas y el pueblo europeo») y en el n. ${ }^{\circ}$ 25/1960 ( «La realidad social española desde el punto de vista europeo») y Jorge Xifra Heras que escribió en el n. ${ }^{\circ}$ 20-23/1957-1958 ( Consideraciones sobre la democracia»).

Otro tanto sucede al contrastar las contribuciones correspondientes a autores de otras disciplinas. Por seguir en las de profesores procedentes del campo del Derecho aunque sus trabajos no siempre versaran sobre temas jurídicos, nos encontramos con Salvador Lissarrague, quien colaboró en el n. ${ }^{\circ}$ 3/1955 ( $\mathrm{El}$ poder social») y con Antonio Truyol Serra, que publicó en el n. ${ }^{\circ}$ 4/1955 ( «La teoría de la monarquía universal de Dante en la lucha de las tradiciones»); en el n. ${ }^{\circ} 8-9 / 1956$ («Nota introductoria al discurso preliminar de Hegel a su Filosofía del Derecho») y en el n. ${ }^{\circ} 13-15 / 1956$ ( «El Discorso della neutralità, de Botero en su relación con la teoría de la neutralidad en Maquiavelo y Bodino»). Por su parte, Mariano Hurtado Bautista colaboró en el n. ${ }^{\circ}$ 10-12/1956 («El «système des lumières» y la filosofía de la historia en el pensamiento social y jurídico de $\mathrm{H}$. Saint Simon»); Elías Díaz verá publicados varios trabajos suyos: en el n. ${ }^{\circ}$ 28/1963 («Fascismo y neofascismo»); en el n. ${ }^{\circ} 29-30 / 1963$ ( Nota sobre la encíclica Pacem in terris»); y en el n. ${ }^{\circ} 31 / 1964$ («Sociedad de masas y sistemas políticos contemporáneos»); y Luis García San Miguel escribió en el n. ${ }^{\circ}$ 31/1964 («Reflexiones sobre el amor en el cine de Antonioni»).

Los penalistas José María Rodríguez Devesa, en el n. ${ }^{\circ}$ 16-19/1957 ( «La nueva Ley Penal Militar Alemana») y Marino Barbero Santos, en el n. ${ }^{\circ} 24 / 1959$ ( «Consideraciones sobre el estado peligroso y las medidas de seguridad con especial referencia al Derecho italiano y alemán»), se unirán al elenco de autores. En 
esta misma disciplina se encuadran los textos de Miguel Peydró Caro en el n. ${ }^{\circ}$ 25/1960 ( «Tipos delincuentes e ideas penales en la obra de Albert Camus») y de Antonio Peláez de las Heras en ese mismo número ( Apuntes de criminología»). Manuel Medina Ortega, internacionalista, escribió en el n. ${ }^{\circ}$ 26/1962 («Una nueva concepción en el Derecho Internacional: el sociologismo de Myres S. McDougal»); en el n. ${ }^{\circ}$ 27/1962, junto con Robert E. Stein ( «La crisis financiera de las Naciones Unidas») y en el n. ${ }^{\circ}$ 32/1964 («El derecho de asilo diplomático en España»). También nos encontramos con parte de la tesis doctoral de Jesús Ruipérez Juárez en el n. ${ }^{\circ}$ 31/1964 («La definición de represalias en el Derecho Internacional vigente»).

Colaborarán igualmente los administrativistas Enrique Martínez Useros en el n. ${ }^{\circ} 7 / 1955$ («Derecho, política e intervencionismo administrativo») y Juan Domínguez Berrueta en el n. ${ }^{\circ}$ 13-15/1956-1957 ( La reforma de la Administración») y en el n. ${ }^{\circ}$ 16-19/1957 («La intervención estatal en la vivienda»). El romanista Alfredo Calonge Matellanes lo haría en el n. 32/1964 («Henry Lévy-Bruhl») al que ya hemos aludido más arriba. Y el historiador del Derecho Ignacio de la Concha publicó en el n. ${ }^{\circ}$ 6/1955, el artículo «De los partidos políticos en EE.UU. El partido republicano». En fin, los laboralistas Rafael Borrego Castaño y Manuel Pena López participaron en el n. ${ }^{\circ}$ 20-23/1957-1958 ( Responsabilidad civil y riesgos profesionales»).

Es bien significativa, además, la contribución de Niceto Alcalá-Zamora Castillo en el n. ${ }^{\circ}$ 29-30/1963 ( «El mandado de seguridad brasileño, visto por un extranjero»).

Si de los profesores de Derecho pasamos a los de los otros ámbitos de las Ciencias Sociales, nos encontramos con un panorama parecido. Luis Díez del Corral participa en el n. ${ }^{\circ} 8-9 / 1956$ («La actitud sociológica ante el arte español») y José Antonio Maravall lo hizo en el n. ${ }^{\circ}$ 10-12/1956 ( «La idea de cuerpo místico en España antes de Erasmo»). Luis Sánchez Granjel escribió en el n. ${ }^{\circ}$ 5/1955 («Las ideas antropológicas de Herván y Panduro»); y Juan José Linz, junto a Amando de Miguel, publicaron en el n. $31 / 1964$ («Origen social de los empresarios»). Antes hay que destacar la contribución del murciano Miguel Espinosa Gironés, en el n. ${ }^{\circ}$ 10-12/1956 («La filosofía política mandarinesca»). Es un ensayo que, al decir de los editores, se publicó por estar vinculado al género utópico, la importancia del cual en el desarrollo del pensamiento político destacaron. Se trataba de un capítulo de su libro Escuela de mandarines ${ }^{31}$.

Vicente Cervera Tomás, escribió en el n. ${ }^{\circ}$ 6/1955 («En torno al ensayismo»). Juan Ángel di Meglio colaboró en el n. ${ }^{\circ}$ 16-19/1957 («Desde el racionalismo como conclusión de la filosofía jurídica moderna a la teoría política de Manuel

31 Morodo, R., Atando cabos, cit. pp. 202 y sigs. dice del libro que «entre novela y ensayo», era «en realidad una utopía/antiutopía de la transgresión y feroz crítica encubierta a la sociedad y cultura política franquista». También destaca que E. Tierno dijo de M. Espinosa que «es el más claro renovador de las letras españolas del siglo $\mathrm{xx}$ ». 
Kant») y, también, José Luis Ugarte («Bienestar para todos»). En el n. ${ }^{\circ}$ 27/1962 participó Manuel Durán — profesor de la Universidad de Yale— ( «Ortega y su definición de los fenómenos sociales») y en el n. ${ }^{\circ}$ 28/1963 colaboró con una nota Luis Jiménez Moreno («Individuo y sociedad en Nietzsche»), que había defendido un año antes bajo la dirección de José Luis López Aranguren su tesis doctoral sobre «El pensamiento antropológico de Nietzsche». Y Alberto Míguez escribió en el n. ${ }^{\circ}$ 31/1964 ( «Cuatro notas sobre los intelectuales»).

Por su parte, Salustiano del Campo Urbano colaboró en el n. ${ }^{\circ}$ 16-19/1957 («Tendencias generales de la fertilidad en España») y José Carlos García Bernalt en el n. ${ }^{\circ}$ 20-23/1957-1958 ( «Movimiento migratorio de obreros agrícolas en la provincia de Salamanca»). Ya se ha mencionado la contribución de Salvador Giner en el n. ${ }^{\circ}$ 28/1963 («Comentarios liminares sobre la llamada sociedad de masas») y José Luis Abellán participará en el n. ${ }^{\circ} 31 / 1964$ («La novela personal de Antonio Machado»). Víctor Pérez Díaz intervino también en el n. ${ }^{\circ}$ 31/1964 («Encuesta sobre la vida militar») e Ignacio Sotelo escribió en el n. ${ }^{\circ}$ 28/1963 («Polémica sobre el neonormativismo»), en el n. ${ }^{\circ}$ 29-30/1963 («Merleau Ponty y la Política») y en el n. ${ }^{\circ} 32 / 1964$ («Sartre y el marxismo»). Gabriel Tortella contribuyó al n. ${ }^{\circ}$ 32/1964 ( «Reflexiones en torno al imperialismo norteamericano en 1898») y Juan Gerona en el n. ${ }^{\circ}$ 29.30/1963 a propósito del turismo escribió una nota («La gallina de los huevos de oro»).

Cabe recordar aquí a los que, sin pertenecer a la dirección ni formar parte de sus colaboradores inmediatos, fueron los más asiduos autores del Boletín. Se trata de José Luis Fernández de Castillejo, quien contribuirá en seis números como autor. Lo hizo en el n. ${ }^{0}$ 3/1955 («Sociedad y enfermedad»); en el n. ${ }^{0}$ 5/1955 ( «Sobre una sociología de la institución»); en el n. ${ }^{\circ}$ 10-12/1956 («El nuevo y el viejo Wittgenstein»); en el n. ${ }^{\circ}$ 24/1959 ( «Nota sobre dos publicaciones filosóficas recientes»); en el n. ${ }^{\circ}$ 25/1960 («La filosofía lingüística»); y en el n. ${ }^{\circ}$ 32/1964 («De Velázquez a Tapies»). Y de César Armando Gómez que escribió en cinco números: en el n. ${ }^{\circ}$ 8-9/1956 («La filosofía política de "El espectador"»); en el n. ${ }^{\circ} 10-12 / 1956$ ( «Democracia y revolución en la formación de la URSS»); en el n. ${ }^{\circ}$ 13-15/1956-1957 («Economía y libertad»); en el n. ${ }^{\circ}$ 20-23/1957-1958 («Europa como programa») y en el n. ${ }^{\circ} 25 / 1960$ («Destino de la revolución»).

En el campo de las Humanidades pueden encuadrarse las contribuciones de Santiago Montero Díaz en el n. ${ }^{\circ}$ 24/1959 ( «La juventud romana en torno a Catilina») y en el n. ${ }^{\circ}$ 25/1960 ( «Ni Spengler ni Toynbee»); de Agustín García Calvo en el n. ${ }^{\circ} 8-9 / 1956$ ( «Sobre un nuevo libro de Zürcher»); de Jorge Enjuto Bernal en el n. ${ }^{\circ} 29-30 / 1963$ ( Filosofía y poesía») y en el n. ${ }^{\circ}$ 32/1964 ( «La filosofía de Alfred North Withehead»); y de Javier Muguerza en el n. ${ }^{\circ} 31 / 1964$ ( «Semántica y marxismo en la encrucijada filosófica de Polonia»). Por su parte, Armando Zubizarreta escribió en el n. ${ }^{\circ}$ 20-23/1957-1958 ( «Una desconocida «Filosofía lógica» de Miguel de Unamuno»).

Miguel Cruz Hernández participó en el n. ${ }^{\circ}$ 20-23/1957-1958 («La justificación de la monarquía según Ibn Hazm de Córdoba»). Manuel Tuñón de Lara 
colaboró en el n. ${ }^{\circ}$ 29-30/1963 ( «La oposición juzgada por el poder como fuente de la Historia») y en n. ${ }^{\circ}$ 32/1964 («1929: el último año de la Dictadura»). Eduardo Martínez de Pisón contribuyó en el n. ${ }^{\circ}$ 31/1964 («La formación de los suburbios madrileños en el paso del siglo XIX al siglo XX»). José Aumente, en el n. ${ }^{\circ} 29-30 / 1963$ («España y Latinoamérica. Algunos de sus problemas comunes»). Y Bartolomé Escandell Bonet en el n. ${ }^{\circ}$ 20-23/1958 («En torno a Qumram»). Antes, José Luis García Rúa escribió en el n. ${ }^{\circ}$ 6/1955 ( «De los matices del interés existencial romano hasta el siglo I de Cristo») y María del Carmen de Guzmán Pla en el n. ${ }^{\circ}$ 10-12 («Ideas político-económicas de José del Campillo y Cossío»).

Por su parte, Fernando Lázaro Carreter participará dos veces: en el n. ${ }^{\circ}$ 8-9/1956 ( «Temas de hoy: teatro y sociedad en España») y en el n. ${ }^{\circ}$ 16-19/1957 («Bertold Brecht y el teatro épico»). Joaquín Gimeno Casalduero colaboró en el n. ${ }^{\circ}$ 8-9/1956 («El tópico en la obra de Pérez Galdós»); Claudio Guillén escribirá en el n. ${ }^{\circ}$ 27/1962 («Perspectivas de la literatura comparada»); Gonzalo Sobejano lo hará en el n. ${ }^{\circ}$ 31/1964 («Sobre la novela picaresca contemporánea»); Emilio Salcedo ${ }^{32}$ en el n. ${ }^{\circ}$ 26/1962 [ «Judíos y cristianos (Notas sobre La Celestina»)]; Francisco Alemán Sáinz, en el n. ${ }^{\circ}$ 5/1955 («El mundo novelesco de Julio Verne (En el cincuentenario de su muerte»); en el n. ${ }^{\circ}$ 8-9/1956 («La razón maquinante o la novela de folletín»); en el n. ${ }^{\circ} 10-12 / 1956$ ( Para una teoría del terror»); Germán de Argumosa en el n. ${ }^{\circ}$ 16-19/1957 («Espacio y tiempo en Edgar Allan Poe») al igual que Juan José López Cabanela ( «Merejkoski y los dioses») quien, además, colaboró en el n. ${ }^{\circ}$ 20-23/1957-1958 ( «El suicidio en la literatura contemporánea») y en el n. ${ }^{\circ}$ 24/1958-1959 («Las ideas del doctor Jivago»); y José María Castellet, en n. ${ }^{\circ} 28 / 1963$ («Notas para una caracterización del movimiento simbolista»).

Otros autores, como Fernández de Castillejo, sin pertenecer al mundo universitario, hicieron aportaciones desde sus posiciones intelectuales y profesionales. Es el caso de Dionisio Ridruejo que colaboró en el n. ${ }^{\circ}$ 24/1959 ( «La Europa que se proyecta») y, también, el de Fernando Morán López que participó en los n. ${ }^{\circ}$ 8-9/1956 («España y la integración europea: la integración agrícola»); en el n. ${ }^{\circ} 13-15 / 1956$ («El desarrollo económico»); en el n. ${ }^{\circ}$ 20-23/1957 («Una defensa de la diplomacia clásica»); en el n. ${ }^{\circ}$ 24/1959 ( Dos libros sobre la evolución de la IV República Francesa»); y en el n. ${ }^{\circ}$ 28/1963 («La política exterior de la IV República Francesa»).

Se pueden recordar igualmente los textos de Rafael Rodríguez Delgado ( «Los nuevos objetivos del hombre»), parte de una investigación de la Society for General Systems Research, quien, además, publicó otras notas en el n. ${ }^{\circ}$ 29-30/1963 y en el $n .^{\circ} 31 / 1964$ sobre («Las instituciones de la paz») y un artículo en el n. ${ }^{\circ}$ 31/1964 («Un plan para la organización de la paz»). Ramón Villanueva participó en el n. ${ }^{\circ}$ 8-9/1956 («La unidad geopolítica de Europa») y en el n. ${ }^{\circ}$ 13-15/1956-1957 («El Eurátomo. Instituciones del Mercado Común y del Eurátomo»); José Luis de la Guardia en el n. ${ }^{\circ}$ 10-12/1956 («Estado actual de la

32 Con ese nombre firmaba E. Sánchez Arteaga. 
Unión Funcional Europea»); Santiago Alba Govillar en el n. ${ }^{\circ}$ 13-15/1956-1957 («El Tratado del mercado común europeo»). Asimismo, Gonzalo Puente Ojea escribió en el n. ${ }^{\circ}$ 13-15/1956-1957 («Liberalismo y democracia, vistos por un católico»); Enrique Larroque en el n. ${ }^{\circ} 13-15 / 1956 / 1957$ («El problema sociológico de los bloques internacionales»); José María Sierra Navas en el n. ${ }^{\circ}$ 16-19/1957 («Panorama actual del Consejo de Europa»), Leandro Rubio García en el n. ${ }^{\circ}$ 16-19/1957 («Ojeada sobre los experimentos de una «democracia popular». Balance de un año de gomulkismo»). Asimismo, contribuyeron Moisés Toledo en el n. ${ }^{\circ}$ 20-23/1957-1958 ( Reflexiones sobre ciertos rasgos comunes a los europeos en cuanto fundamentos de la Federación Europea») y Gonzalo Sáez de Buruaga en el n. ${ }^{\circ} 24 / 1958-1959$ («Sobre el problema meridional italiano»).

A los autores mencionados hasta ahora se han de añadir los que se encargaron de elaborar las recensiones, reseñas y bibliografías que aparecen en las páginas de los 32 números publicados. Hacer mención debida de todos ellos requeriría la investigación que auspicia Raúl Morodo ${ }^{33}$, pero no es el propósito de estas páginas que buscan solamente esbozar el significado y el contenido de la aventura en que consistió el Boletín ${ }^{34}$.

\section{La aportación extranjera al Boletín}

Ya he recordado que el primer artículo publicado fue el de Carl Schmitt, en n. ${ }^{\circ}$ 2/1955 y que el último número, el n. ${ }^{\circ}$ 32/1964 recogía colaboraciones de

33 Morodo, R., Atando cabos, cit., p. 150.

34 Sí he podido establecer la relación siguiente, que no es completa porque los autores de recensiones en ocasiones firmaban con sus iniciales y algunas, pocas, no he conseguido completarlas. En cambio, sí he incluido a los miembros del equipo de dirección pues su participación en esta tarea corrobora el empeño que pusieron en sacar adelante el Boletín. En orden alfabético y con indicación del número o números en que colaboraron, algunos de ellos con varias recensiones, son los siguientes: Álvarez, T. (32); Andrino Hernández, M. (5, 6, 7, 13-15, 16-19, 20-23, 25, 26, 28); Argumosa, G. de (5, 10-12); Arteagabeitia, J.J. (32); Beiras, J.M. (28); Bejarano, V. (8-9); Blasco, J. (29-30); Brown, F.F. (26); Camiroaga de la Vega, A. (16-19); Cobaleda González, J.M. (10-12); Calonge Matellanes, A. (5, 7, 8-9, 10-12); Chiriboga Vascónez, F., (5, 13-15, 16-19); Cores Trasmonte, B., (25); Cortés, C., (24); Cortés Bretón y Sierra, E., (5, 7, 20-23); Cueva, J., de la (1); Díaz, E., (27, 28, 31, 32); Fernández Giménez, P., (27); Fontiveros Carrasco, F., (7, 8-9, 10-12); Esteve, M., (31); García Lozano, C., (4, 5, 6); Garaycoa, J.J., (25); Garzaro, R., (13-15, 16-19, 20-23, 24); Garzón Garzón, D., (2); Gil Nieto, F., (1, 2, 3, 4, 6, 7, 13-15); Gil Robles, J., (16-19); Giner, S., (29-30); González López, E., (8-9, 10-12); González, L.A. (3, 4, 7); González Suárez, A., (7); Hernández Nieto, R., (4, 7); L. de Yturbe, F. (28, 29-30, 31, 32); Jiménez Moreno, L., (28); Juan Martín, Á., de (24); Lázaro Carreter, F., (7); López Cabanela, J.L., (8-9, 20-23, 24, 25); Lucas Verdú, P., (1, 2, 3, 5, 6, 7, 8-9, 10-12, 13-15, 31); Lugrís, R., (29-30); Marcos Jiménez, M., (10-12); Martínez Cuadrado, M., (27); Medina Ortega, M., (24, 26); Míguez, A., (27); Morodo, R., (1, 2, 3, 4, 5, 6, 7, 8-9, 13-15, 16-19, 20-23, 24, 25, 26, 29-30); Núñez Madriz, J., (3); Ortega Herráiz, L., (4); Roberts, L., (27, 31); Rodríguez Sáinz, J., (2, 6); Roggero, A., (25); Sánchez Ramírez, X., (8-9); Sastre Aseguinolaza, A. (8-9); Serrano, A., (8-9); Sierra Bravo, R. (24); Sobejano Esteve, E., (6); Solana Prellezo, F., (2, 3, 5, 6, 7, 8-9, 10-12, 16-19, 20-23, 24, 25); Sotelo, I., (29-30); Talavera, J.M., (24); Tierno Galván, E., (1, 2, 5, 6, 7); Triana, E., (31); Uitti, K.D., (31); Vega García, P. de (13-15, 25); Vera Urbano, F., (6); Vidal Frances, P., (4, 8-9); Vitoria, L., (8-9); Zaballos, B., (13-15, 16-19); Zavala, I.M. (29-30). 
cinco extranjeros: Rohrmoser, Hauser, Callahan, Miliband y Martinet. Hay que decir que, a partir del n. ${ }^{\circ} 3$, habrá siempre, al menos, un artículo de un autor no español y, las más de las veces, serán varios.

Así, el entonces profesor de la Universidad de Génova, Luigi Bagolini, encabeza el n. ${ }^{\circ}$ 3/1955 con este artículo «Utilidad y límites de la sociología para la valoración en términos de justicia distributiva»; Hans Freyer, en aquél momento en Wiesbaden, abre el n. ${ }^{\circ}$ 4/1955 con el artículo «El hombre y el orden social del presente»; y el artículo de Michael Albery, profesor de la Universidad Católica de Boston, «Orientaciones de la educación universitaria en los Estados Unidos», es el primero del n. ${ }^{\circ}$ 5/1955. El n. ${ }^{\circ} 6 / 1955$ incluye una nota con la traducción del texto de Pietro Virga sobre «La separación de poderes». El n. ${ }^{\circ}$ 7/1955 comienza con la traducción del artículo de Cyrill K. Krasinski «Sobre la crisis del moderno concepto de propiedad privada», publicado en Freiburger Zeitschrift für Philosophie und Theologie, n. ${ }^{\circ} 1 / 1954$. El n. ${ }^{\circ} 8-9 / 1956$ incluye un artículo del profesor de la Universidad de Graz Endre V. Ivanka sobre «Naturaleza y desarrollo histórico de la nación austríaca». Es la traducción del publicado en el n. ${ }^{\circ}$ 4/1955 de la revista Humanitas, de Brescia. Asimismo, incluye la nota de Helmut Schoeck: «El mal de ojo. Forma y dinámica de una superstición universal». Es la traducción del texto publicado en el Emory University Quarterly, n. ${ }^{\circ} 1955$. Y el n. ${ }^{\circ} 10-12 / 1956$ comienza con el artículo de Hans Kelsen «Causalidad e imputación», traducción del publicado en el n. ${ }^{\circ} 2 / 1953$ de Oesterreischische Zeitschrift für Öffentliches Recht, de Viena y, luego, recoge una nota de Eduard Zellweger sobre «La dictadura del proletariado», traducción de la publicada en el n. ${ }^{\circ}$ 3/1955 del Bulletin de la Commission Internationale de Juristes.

A partir del n..$^{\circ}$ 13-15/1956-1957 la tónica será que aparezcan varias colaboraciones de autores extranjeros en cada número. Así, en ése, el primero es de Sacha Nacht, René Diatkine y Paul Claude Racamier, «Psicoanálisis y Sociología». Además, están el artículo Joseph Roucek «La revisión de la diplomacia tradicional por la Rusia soviética»; el de Georges Lapassade «La filosofía de J.J. Rousseau. Estructura y unidad»; el de Joseph Margolis «Todos los hombres han sido creados iguales»; y el de Jason Xenakis «La lógica de la ficción». Salvo el de Roucek, los otros cuatro son traducciones de los textos publicados, respectivamente, en las revistas La Nef, julio/1956; Revue de Metaphisique et de Morale n. ${ }^{\circ} 3-4 / 1956$; The Journal of Philosophy n. ${ }^{\circ}$ 13/1955; y Methodos n. ${ }^{\circ} 29-30 / 1956$.

El n. ${ }^{\circ}$ 16-19/1957 comienza con el artículo de Henri Gouhier «El análisis histórico según Augusto Comte», escrito en la conmemoración de su centenario. Le sigue el de Haruo Naniwada «Smith-Hegel-Marx. Sobre la íntima dependencia de sus doctrinas filosófico-sociales», publicado en Zeitschrift für die gesammte Staattswissenschaft, tomo III/1955. Después, está la traducción del obituario de Ludwig Wittgenstein publicado en The Australasian Journal of Philosophy (vol. XXIX, n. ${ }^{\circ}$ 2/1951); el artículo de W.J. Matson «Hume y el libre albedrío», traducción del publicado en MIND, vol LXV, n. ${ }^{\circ}$ 260/1956; y el texto de Adlai Stevenson «La secuela del colonialismo», traducido de la revista Optima, Unión 
Sudafricana, en el número de diciembre de 1957. En la sección de Europa a la vista incluye el trabajo de Ian A. Lawson «Introducción a William Blake».

En el n. ${ }^{\circ}$ 20-23/1957-1958 el artículo de Paul Oppenheim «Las dimensiones del conocimiento» es el primero. Se tradujo de la Revue internationale de Philosophie n. ${ }^{\circ}$ 40/1957. Le sigue el de Pierre Dubois «La actitud de J. Wisdom en relación a la metafísica», traducido de la Revista Portuguesa de Filosofía, t. XIV, n. ${ }^{\circ}$ 2; y el de Frederik C. Engelmann, «Crítica de los últimos estudios sobre los partidos políticos», traducido de The Journal of Politics, vol. 19, n. ${ }^{\circ}$ 3/1957.

El n. ${ }^{\circ} 24$ recoge cinco artículos de autores extranjeros. El primero es el de David E. Apter «Método comparativo para el estudio de la política», traducido de The American Journal of Sociology, vol. LXIV, n. ${ }^{\circ} 3 / 1958$; a continuación, está el de Mario Linz «La Sociología del Conocimiento. Aspectos de su problemática», traducido de la Revue Internationale de Sociologie, vol. I n. ${ }^{\circ} 2-3 / 1958$; después aparece el de Hans-Joachim Lieber y Peter Ludz «Estado actual de la investigación marxista», traducción del texto publicado en el Kölner Zeitschrift für Soziologie und Sozial Psychologie, 1958. El siguiente es de Nicolas Timasheff «Teoría e investigación empírica en la Sociología americana», traducido de la Revue de lTnstitut de Sociologie Solvay, 1957. En fin, Adolf von Wagner publica «El sistema constitucional de los partidos políticos en Alemania» y Roger Munier «Notas sobre una visita a Heidelberg».

De nuevo, el n. ${ }^{\circ}$ 25/1960 es encabezado por autores extranjeros. William Ebenstein, profesor de la Universidad de Princeton, publica «John Stuart Mill en nuestros días»; incluye la segunda parte del estudio de Hans Joachim Lieber y Peter Ludz sobre «Estado actual de la investigación marxista»; y el texto de Georg Lukács «Historia y conciencia de clase». Es una traducción del facilitado por el Institut für Sozial Forschung de la Universidad de Frankfurt. En cambio, el n. ${ }^{\circ}$ 26/1962 solamente recoge una nota de Edmund L. King, otro profesor de la Universidad de Princeton, sobre «Gabriel Miró y los ejercicios espirituales». En el n. ${ }^{\circ}$ 27/1962 colaboran los profesores de la Universidad de Princeton Karl D. Uitti («Poesía y visión política en la Chanson de Roland»); y José Schraibman («Patria y patriotismo en los Episodios Nacionales de Galdós»); y, además, Robert E. Stein, profesor de la Universidad de Columbia, escribe con Manuel Medina Ortega ( «La crisis financiera de las Naciones Unidas»). Y en el n. ${ }^{\circ}$ 28/1963 solamente contribuye Pierre-Marie Juret ( A la búsqueda de una interpretación matemática de una encuesta política según el método del escalograma de Guttman»). Se trata de la traducción del texto publicado en la Revue du Droit Public et de la Science Politique en France et à l'étranger, n. ${ }^{\circ}$ de mayo-junio/1962.

En los tres últimos volúmenes publicados vuelven a ser varios los trabajos de autores extranjeros. Así, el n. ${ }^{\circ}$ 29-30/1963 incluye los del profesor puertorriqueño Herbert Marty Torres ( «El papel de algunos estratos de la clase media en el curso del nacionalismo en el África Occidental»); el de los profesores de la Universidad Nacional Australiana Geoffrey Sawer y Günther Doecker ( «La 
Comunidad Económica Europea como sistema constitucional»), traducción de Inter-American Law Review, vol. IV, n. ${ }^{\circ}$ 2/1962; y el de Norman Z. Alcock («El Puente de la razón»).

En el n. ${ }^{\circ} 31 / 1964$ aparece el trabajo de Manuel Maldonado Denis, profesor de la Universidad de Río Piedras de Puerto Rico, «C. Wright Mills (1916-1952): sociólogo crítico y crítico de la sociología». Además, contiene el artículo del profesor de la Universidad de Princeton Edmund L. King, "¿Qué es el romanticismo?»; y el de André Gorz «Los niveles de lucha». Se trata este último de la traducción de una parte del artículo publicado en el n. ${ }^{\circ}$ 211/1963 de Les Temps Modernes con el título «Estrategia de los monopolios y estrategia obrera en el Mercado Común». Además, la filóloga puertorriqueña Iris M. Zavala publicó una nota sobre «Entrañamiento y extrañamiento unamunianos».

En fin, el n. ${ }^{\circ} 32 / 1964$, tal como se ha anticipado, contiene el texto de Günther Rohrmoser «La teoría del Estado en Hegel y el problema de la libertad en la sociedad contemporánea», traducción de una conferencia pronunciada en la Universidad de Giessen, a su vez ampliación de su intervención en el Hegel-Kongress celebrado en Heidelberg en 1962 y publicada en Beibeft der Hegel Studien, Bonn, 1964. También recoge el trabajo de Richard Hauser «Las trayectorias de la paz»; el del profesor de la Universidad de Harvard de W.J. Callahan «Conflictos laborales en el siglo XviII»; el de Ralph Miliband, profesor de la London School of Economics, «Programa de una política laborista» y el de Gilles Martinet, director del semanario parisino France Observateur, «El porvenir del gaullismo». Estos dos últimos textos fueron traducidos del n. ${ }^{\circ} 1 / 1963$ de la Revue Internationale du socialisme.

\section{LA IMPRESIÓN DE CONJUNTO}

El examen del conjunto de autores y de los asuntos sobre los que tratan los textos que de ellos publicó el Boletín pone de manifiesto su plural procedencia intelectual e ideológica, combina aportaciones de religiosos con las de teóricos del marxismo, corrobora la talla ya entonces indiscutida de algunos - basta con citar a Schmitt, Kelsen, o Apter, entre los extranjeros o a Ruiz del Castillo, Pérez Serrano, Lissarrague, Truyol Serra, Díez del Corral, Maravall entre los españoles- y la variada gama de temas abordados con claro predominio de los propios de la Filosofía y de las ciencias sociales frente a los propiamente jurídicos, reducidos a la mínima expresión.

Es verdad que la mayor parte de los artículos y notas de autores no españoles fueron traducciones de textos ya aparecidos en revistas o publicaciones de otros países. No obstante, esa circunstancia, que obedece a los modestos medios con que se editaba el Boletín y, en general, a las condiciones de la investigación en España en aquella época, al tiempo que muestra la iniciativa de quienes los seleccionaron y tradujeron, miembros del equipo directivo o sus colaboradores, no le resta valor. Es 
decir, no altera el hecho de que, de ese modo, facilitó el acceso a autores e ideas muchos de los cuales no habrían encontrado acomodo en otras publicaciones españolas. Ya se han visto las opiniones no sólo de quienes participaron de diversa forma en el Boletín, sino también la de quienes sin haberlo hecho coinciden en destacar que sirvió para dar a conocer en nuestro país nuevas líneas y formas de pensamiento.

La comparación entre los autores y los temas que en el mismo período aparecen en la Revista de Estudios Políticos y el Boletín en los años en que se publicó éste (1954-1964), es un buen modo de confirmar las anteriores apreciaciones. Ambos comparten, ciertamente, carácter enciclopédico y habrá quienes colaboren en las dos publicaciones ${ }^{35}$. No obstante, es clara su diferente orientación. En la revista del entonces Instituto de Estudios Políticos se publicaron, desde luego, textos rigurosos de autores de prestigio españoles y extranjeros, pero también otros, obra de exponentes del Régimen imperante que no aparecen obviamente en el Boletín. Y, pese a publicar textos relevantes de autores europeos y americanos importantes en los campos del Derecho Constitucional, la Ciencia Política y la Sociología, no tuvo la Revista de Estudios Políticos el aire renovador y la proyección europeísta que, hemos visto, se reconocen al Boletín.

Ciertamente, son más los que escribieron en la Revista de Estudios Políticos que los que lo hicieron en el Boletín, pero hay que tener en cuenta que tenía aquélla una periodicidad bimensual real y que, por tanto, en el período que va desde finales de 1954 hasta el fin de 1964 publicó más números efectivos que el Boletín: frente a los veinte de este último, fueron cincuenta y cinco los volúmenes de la Revista que aparecieron. Y, naturalmente, la Revista de Estudios Políticos no tuvo que hacer frente ni a las limitaciones económicas ni a los obstáculos políticos que sí encontró el Boletín. Estas circunstancias facilitaron que la Revista captara contribuciones y realizara traducciones. Además, su mejor distribución era un atractivo añadido para los autores extranjeros, pues les aseguraba una amplia difusión de sus trabajos en lengua española.

En cualquier caso, el Boletín resiste la comparación con la Revista desde el punto de vista principal, el de los contenidos y el de la influencia que ejerció. Representó una forma distinta de aproximarse al quehacer universitario: sin ataduras ni otras restricciones internas distintas de las derivadas del propio criterio en el desarrollo del estudio y de la investigación. Favoreció una actitud abierta pero crítica y rigurosa sin confundir la seriedad en el trabajo académico con el formalismo o la jerarquía. La mejor muestra de su éxito, conviene reiterarlo, está en los logros de todo tipo que alcanzarían andando el tiempo los jóvenes que se reunieron en torno a Tierno Galván y sus colaboradores en el Seminario de Derecho Político de la Universidad de Salamanca e hicieron posible su Boletín Informativo.

35 Son los siguientes: Del Campo Urbano, S. del; Díaz, E.; Diez Del Corral, L.; Espinosa, M.; Freyer, H.; García San Miguel, L.; Giner, S.; Larroque, Linz, J.J.; Lissarrague, S.; Lucas Verdú, P.; Maravall, J.A.; Martínez Cuadrado, M.; Medina Ortega, M.; De Miguel, A.; Morodo, R.; Pérez Serrano, N.; Roucek, J. S.; Rubio García, L.; Ruiz Del Castillo, C.; Schmitt, C.; Truyol Serra, A.; Xifra Heras, J. 


\section{LAS RAZONES DE SU SUPERVIVENCIA.}

No había duda de que Tierno Galván no era una persona adepta al Régimen. Igualmente, se conviene en que en el Seminario de Derecho Político de la Universidad de Salamanca y con su Boletín, comenzó a forjar un grupo político que adquirió personalidad propia en el seno de la oposición democrática al franquismo ${ }^{36}$. Es más, Tierno Galván y Raúl Morodo fueron detenidos y encarcelados en $1957^{37}$. Siendo esto así, la pregunta que surge es la de cómo se pudo publicar durante nada menos que diez años un Boletín, obra de quienes claramente propugnaban y difundían ideas contrarias sobre las que descansaban las instituciones políticas imperantes y se vieron plasmadas, en 1958, en la Ley de Principios del Movimiento Nacional.

Raúl Morodo destaca el título inocuo elegido: un «Boletín Informativo», observa, no debía llamar la atención ${ }^{38}$. Tierno apunta a la forma de eludir los censores más rigurosos ${ }^{39}$. Por otro lado, se ha hablado de la ocultación y el disimulo, del uso del lenguaje camuflado y del neotacitismo de Tierno Galván como actitud defensiva $^{40}$, de su personalidad críptica ${ }^{41}$. Morodo se ha extendido al respecto ${ }^{42}$. Sin duda, pudo imprimir al Boletín ese sesgo pues está claro que en él no se hacían llamamientos a la subversión ni había una crítica directa a los gobernantes ni al Estado construido tras la Guerra Civil, pero, también, hay otras razones que ayudan a explicar la pasividad de las autoridades frente a él.

El Boletín fue una publicación científica, propia de especialistas. No era un vehículo de información al público en general sino de profundización en contenidos dotados de la complejidad habitual en el quehacer académico. Su difusión, pues, se limitaba a quienes se movían en ese ámbito, por definición muy reducido.

36 Así lo apunta Tusell, La oposición democrática al franquismo, cit., pp. 355 y, por lo demás, es un hecho generalmente reconocido.

37 Morodo, R., Atando cabos, cit., pp. 183 y sigs evoca esa experiencia y recuerda que también fueron detenidos entonces otros colaboradores del Boletín como Fermín Solana Prellezo, Ignacio Sotelo y Germán de Argumosa (p. 186). Y que el proceso penal concluyó en 1961 sin condena gracias al indulto concedido con motivo de la elección del Papa Juan XXIII (p. 242).

38 Morodo, R., «Enrique Tierno: semblanza, aventura y compromiso político-intelectual», cit. p. 11.

39 Gracias a la ayuda del tipógrafo Blázquez, Tierno Galván, E., Cabos sueltos, cit., p. 200. Morodo, R., Atando cabos, cit., p.149, se refiere también a él.

40 Marichal, J., «La voluntad de estilo de Enrique Tierno», en Sistema n. ${ }^{\circ}$ 71-72, cit. p. 104: cuando Tierno funda el Boletín «es un «descendiente» de los tacitistas españoles del siglo XvII, de ahí que me pareciera justificado llamarle «neo-tacitista».

41 Abellán, J.L. [«La personalidad de Tierno como obra de arte», ibídem, pp. 107 y 108] en el largo título del Boletín se ocultan dos de las notas persistentes que caracterizarán la actitud pública de Tierno Galván: «en primer lugar, su carácter críptico, que le lleva a exaltar la figura del «conspirador» frente al «conjurado», tal como analiza dicha contraposición en «Anatomía de la conspiración» [se refiere al artículo publicado en el n. ${ }^{\circ} 27$ del Boletín), en segundo lugar, la preferencia por las formulaciones neutras, asépticas y de índole descriptiva frente a la ideología retórica tradicional».

42 Morodo, R., en Atando cabos, cit. pp. 147 y antes en Tierno Galván y otros precursores políticos. Ediciones El País, Madrid, 1987, pp. 158 y sigs. y 186 y sigs. 
En este sentido, Tusell habla al respecto de «la relativa clandestinidad con que circulan en España las publicaciones periódicas científicas ${ }^{43}$. Si se tienen en cuenta, además, las circunstancias de la época, en las que ni siquiera era habitual disponer de teléfono en el domicilio, se logrará una idea más aproximada de las posibilidades de que las actividades del Seminario de Derecho Político, ciertamente de una Universidad de enorme prestigio pero situada en una pequeña ciudad, tuvieran eco más allá de ese círculo académico y, por tanto, de la proyección que, en términos generales, podía tener el Boletín en la sociedad española de entonces. En otras palabras, el Régimen — que diferenciaba a la hora de la represión entre los distintos sectores de la oposición ${ }^{44}$ — no vio en él un peligro político inmediato.

Cuando Tierno Galván en 1965 adoptó iniciativas de clara proyección pública, tras su suspensión inicial en 1960, fue separado de su cátedra. A esas alturas, además, sus más inmediatos colaboradores ya no estaban en Salamanca. Lucas Verdú, tras varios años en la Universidad de Santiago de Compostela, se hallaba en la Universidad de Deusto, en Bilbao. Y Raúl Morodo se había trasladado a Madrid en 1957. Y será ya desde la capital desde donde Tierno y Morodo prosigan en adelante su actuación política e intelectual. En esas condiciones, como apuntó Ollero ${ }^{45}$, ya no era posible continuar publicando el Boletín.

\section{REFERENCIA FINAL}

Me ha parecido adecuado calificar de aventura la del Boletín Informativo del Seminario de Derecho Político de la Universidad de Salamanca porque fue una empresa ingeniosa, abordada y mantenida a contracorriente por un grupo de profesores sin, prácticamente, más medios que los que fueron fruto de su iniciativa y empeño. Gracias a ellos lograron sortear durante diez años los impedimentos materiales y las cortapisas que frenaban o impedían en la España de la época la libertad de expresión y el pluralismo político y social. $\mathrm{Y}$ en esas circunstancias consiguieron introducir elementos de innovación en las ciencias sociales y, en general, en el pensamiento español. Creo, además, que debieron disfrutar haciéndolo.

Muchos años más tarde, en la Universidad Internacional Menéndez Pelayo, cuando Raúl Morodo fue su Rector entre 1980 y 1983, revivió de algún modo el espíritu del Seminario salmantino y de su Boletín. No sólo intervendrán en sus cursos muchos de los que entre 1954 y 1964 colaboraron en sus páginas, sino que

43 Tusell, La oposición democrática al franquismo, cit. p. 355.

44 Así lo destaca Morodo, R., Atando cabos, cit. pp., 243 y sigs. Tusell, La oposición democrática al franquismo, cit., p. 356, también se refiere a «la acción punitiva relativamente moderada» respecto de Tierno Galván y a la «tolerancia represiva» o «represión tolerante», del Régimen hacia determinados grupos de la oposición democrática (p. 439) entre los que se encontraba el de Tierno Galván.

45 Ollero Gómez, C., «La «idea» de la obra de Tierno y su tensión dialéctica», en Sistema, n. ${ }^{\circ} 71-72 / 1986$, cit. p. 45 
desempeñarán responsabilidades académicas Lucas Verdú y Medina Ortega. Además, en ella Morodo creará la Revista de Política Comparada de la que se editaron once números entre 1980 y $1984^{46}$, en los que se siguieron las mismas pautas observadas por el Boletin. Naturalmente, ni el momento, ni el lugar, ni el contexto político y social tenían nada que ver con la España de mediados de los años cincuenta y principios de los sesenta y tampoco la Universidad Internacional Menéndez Pelayo tenía nada que ver con la Universidad de Salamanca de treinta años antes. Pese a todo ello, sin embargo, el rectorado de Raúl Morodo le aportó un aire de renovación y apertura cultural que enlaza, en un nivel más amplio, con lo que supusieron aquel Seminario de Derecho Político y su Boletín Informativo.

$$
* * *
$$

TITLE: The adventure of the Informative Bulletin of the University of Salamanca Political Law Seminar (1954-1964)

ABstract: The Informative Bulletin of the University of Salamanca Political Law Seminar, created and directed by Enrique Tierno Galvan, assisted by the enthusiastic dedication of his young university collaborators, encouraged the democratic and pro-european concerns they professed and introduced currents of thought that helped to renew the social sciences in Spain. The Bulletin was published for ten years overcoming material difficulties and those that the political regime imposed to the free and plural expression of ideas. Authors from different specialties wrote on its pages, many already renowned at the time, and others that would become renowned later.

Resumen: El Boletín Informativo del Seminario de Derecho Politico de la Universidad de Salamanca, creado y dirigido por Enrique Tierno Galván, asistido por la dedicación entusiasta de sus jóvenes colaboradores universitarios, favoreció las inquietudes democráticas y europeístas que profesaban e introdujo en España corrientes de pensamiento que ayudaron a renovar las ciencias sociales. El Boletín se publicó durante diez años sorteando las dificultades materiales y las que a la expresión libre y plural de las ideas oponía el régimen político imperante. En sus páginas escribieron autores de diversas especialidades, muchos ya entonces intelectualmente reconocidos y otros que lo serán después.

Key wORDs: Spanish University, Political Law, social sciences, academic journal, renewal of thought, democratic opposition.

Palabras clave: Universidad española, Derecho Político, ciencias sociales, renovación del pensamiento, revista académica, oposición democrática.

FECHA DE RECEPCIÓN: 01.09.2020

FECHA DE ACEPTACIÓN: 30.09.2020

46 No será la última de las que creó R. Morodo. Además de haber participado en los Boletines Informativos de Salamanca y de Ciencia Política de la Universidad Complutense y de fundar el del Departamento de Derecho Político la Universidad Nacional de Educación a Distancia, promovió Debate Abierto. Revista de Ciencias Sociales, que publicó entre 1989 y 1992 ocho números. 
